\title{
XCIV. Intra-molecular energy during combustion
}

\section{T. David M.A. D.Sc.}

To cite this article: T. David M.A. D.Sc. (1921) XCIV. Intra-molecular energy during combustion , Philosophical Magazine Series 6, 42:251, 868-870, DOI: 10.1080/14786442108633827

To link to this article: http://dx.doi.org/10.1080/14786442108633827

册 Published online: 08 Apr 2009.

Submit your article to this journal 지

View related articles \ulcorner 
XCIV. Intru-Molecular Energy during Combustion. By W. T. David, M.A., D.Sc., Professor of Engineering, Lniversity College, Carditf**

GOME early experiments of mine with mixtures of coal$\checkmark$ gas and air ignited by means of a spark in a vessel of constant volume showed that the rate at which radiation is emitted is greater during the explosion period (when the bulk of combustion takes place) than at the moment of maximum temperature (when about 90 per cent. of the coalgas has been completely burnt). These experiments were interpreted as supporting the view that the energy of combustion first pisses (either wholly or in a large measure) into the form of intra-inolecular energy of the freshly formed molecules of $\mathrm{CO}_{2}$ and water-vapour, and that the excess of such energy over and above an equilibrium value dependent mainly upon gas temperature is rapidly transformed during mulecular collisions into translational energy $\dagger$.

Later experiments on the aualysis of the radiation emitted during the explosion of mixtures of various strengths seemed to indicate that the intra-molecular energy acquired by the freshly formed molecules during combustion is distributed over their internal degrees of freedom in a manner very much depenlent upon the degree of violence with which combustion takes place. In a previous paper $\ddagger$ it was suggested tentatively that when combustion is gentle the intramolecular energy acquired by these molecules is concentrated in the rotational degrees of freedom and in such very low frequency vibrations as the molecules may be capable of executing, but as the combustion increases in vigour the higher frequency vibrations begin to share in this energy $\S$. I stated in the paper referred to that such a theory would serve to explain many of the phenomena of the pre-pressure and explosion periods in coal-gas and air explosions, and in this paper these phenomena are considered briefly in the lirght of the theory.

Phenomena of the pre-pressure period.-During the prepressure period, which is the interval elapsing between the moment when the igniting spark passes and that when the pressure begins to rise $\|$, a considerable volume of gentle

* Communicated by the Author.

$\dagger$ Phil. Trans. A. vol. 211. p. 410.

t Phil. Mag. Jan. 1920, p. 95.

$\$$ Only those vibrations colresponding to infra-red radiation are referred to.

it The pre-pressure period is not shown in fig. 1. The zero of time is taken to be the moment when the pressure begins to rise. 
inflammation occurs, but no rise of pressure is registered by an indicator or pressure-gaugo. In the gaseous mixtures experimented upon, the number of molecules after combustion is only about 3 per cent. less than that before combustiou. Consequently the translational energy of the freshly formed molecnles during this period is not greater than that of the molecules before ignition took place. There is also no appreciable radiation emitted in this interval, and it follows that no appreciable energy has been acquired by those vibratory degrees of treedom of the freshly formed molecules which give rise to radiation of the kind possessing considerable energy. Assuming, then, that the chemical energy of the inflamed portion of the gaseous mixture has been transformed into thernfal energy of the freshly formed molecules, it would appear that the intra-molecular energy acquired d'ring this interval of gentle burning must be in the form of rotational energy and possibly of low-frequency vibrations, such, e.g., as those corresponding to the $15 \mu$ radiation of $\mathrm{CO}_{2}$ and the much slower vibrations which steam molecules are believed to possess.

Early stage of the explosion period.-In the early stage of the explosion period the pressure at first rises very slowly, indicating that combustion is still proceeding gently. During this time a small, but appreciable, amount of radiation is emitted, as may be seen from curve $F$ in fig. $1^{*}$. This curve shows the radiation from the gaseous mixture which is transmitted through a plate of fluorite - a substance which is highly transparent to all kinds of infra-red radiation down to about $11 \mu$. The curve $Q$ in the same figure shows the radiation transmitted through a plate of quartz which is transparent to infra-red radiation down to about $3.5 \mu$ only $\dagger$. It will be noted that the radiation of the kind transmitted by quartz does not begin to be emitted as early as that of longer wave-length, which is transmitted by fluorite. The theory which has been advanced accounts satisfactorily for this. In the initial stage of the pressure-rise it is to be supposed that the combustion proceeds so gently that the vibrations corresponding to the radiation which is transmitted by quartz are not excited, but it is sufficiently vigorous to excite those corresponding to radiation of longer wave-length. A fraction of a second later, combustion is proceeding sufficiently

* The curves in fig. 1 relate to a 10-per-cent. mixture of coal-gas and air.

$\dagger$ The quartz plate transmits about 70 per cent. of the radiation of wave-length between about $2 \mu$ and $3 \cdot 5 \mu$; it is opaque to radiation of greater wave-length, but is more transparent to radiation of shorter wave-length. 
rigorously to excite, in addition, the vibrations corresponding to the shorter wave-length radiation which is transmitted by (inartz.

Fig. 1.

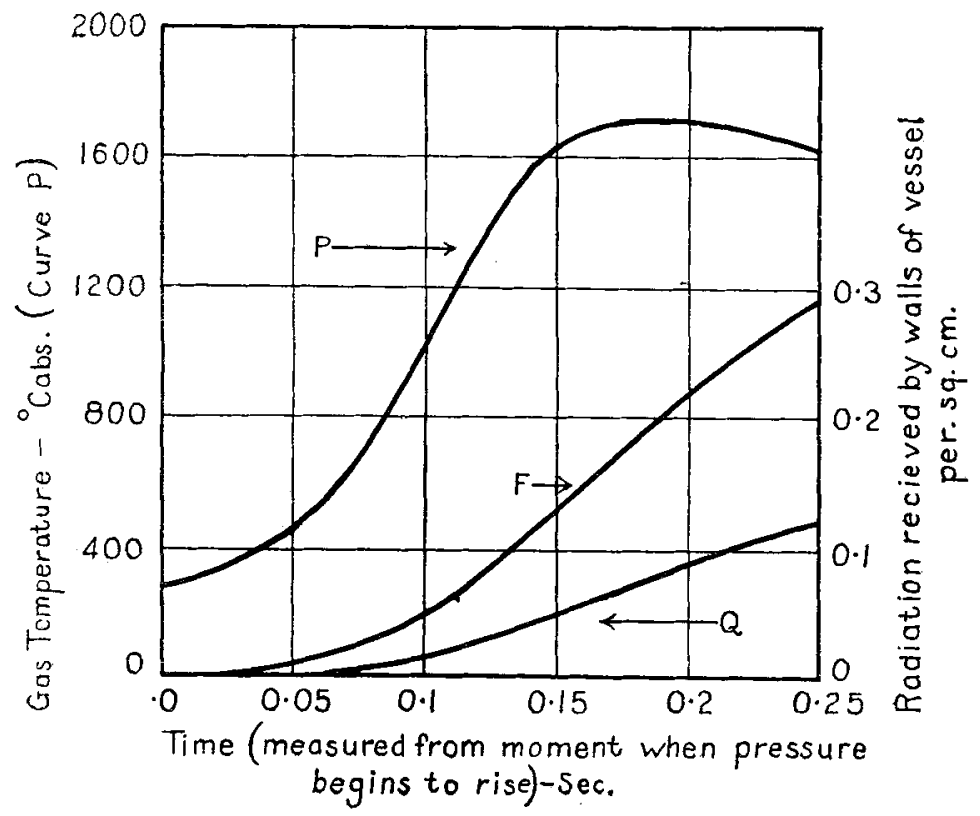

Later stages of the explosion period.-In the later stages of the explosion period, combustion proceeds more vigorously (as is indicated by the rate of rise of pressure or gas temperature--see curve $P$, fig. 1), and in strong mixtures it proceeds, of course, more vigorously than in weak mixtures. The ratio of the radiation transmitted through quartz to that transmitted through fluorite in this epoch is about 055 for a 15-per-cent. mixture, 0.52 for a 12.5 -per-cent. mixture, and 0.46 for a 10 -per-cent. mixtare* ${ }^{*}$ These results go to show that the more vigorously combustion proceeds, the greater the proportion of short wave-length (infra-red) radiation emitted, and therefore the greater the proportion of energy acquired during this period by the vibratory degrees of freedom corresponding to the short wave-length radiation relatively to that acquired by those degrees corresponding to radiation of greater wave-length.

* Phil. Mag. Jan. 1920, p. 86. 